\title{
Comparison of the effect of nigella sativa seeds and powder on lipid profile in Saudi Arabian adults
}

\author{
E. Alamri \\ Department of Nutrition and Food Science, Faculty of Home Economic, University of Tabuk, Saudi Arabia
}

Hyperlipidemia is a risk factor for cardiovascular disease and is a serious public health problem across the world ${ }^{(1)}$. Nigella Sativa (NS) is widely used in traditional medicine and several studies have revealed a positive effect on hyperlipidemia ${ }^{(2)}$. However, there are no studies available in the literature that compare the potentially different effects of NS seeds compared with NS powder on lipids. Therefore, the current study aimed to compare the effect of NS seeds and NS powder on the lipid profile.

An intervention study was conducted among 80 participants aged between 30 and 60 years. They were divided into 3 groups. Group 1 were asked to consume 3 grams/day of NS seeds for 3 months, group 2 were asked to consume 3 grams/day of NS powder for 3 months and group 3 was the control group who were asked not to consume any $\mathrm{NS}^{(3)}$. All participants were subjected to measurement pre and post intervention of total cholesterol (TC), triglycerides (TG), low-density lipoprotein cholesterol (LDL), and high-density lipoprotein cholesterol (HDL).

Data were analysed using SPSS (version 21.0) programme. Chi-square statistics were used to compare the difference between pre and post intervention. A one way ANOVA was used to compare the effectiveness of NS between the 3 groups.

Group 1 and 2 showed a significant reduction in TC, TG and LDL, while HDL increased significantly compared to pre intervention $(\mathrm{p}<0.05)$ (Table 1). Furthermore, the mean differences between pre and post of participants' TC, TG and LDL in group1 were significantly lower than group $2(\mathrm{p}<0.05)$. The mean (SD) differences were $50 \pm 6 \mathrm{mg}, 35 \pm 4 \mathrm{mg}$ and $37 \pm 8 \mathrm{mg}$ for TC, TG and LDL respectively in group 1 compared to $39 \pm 8 \mathrm{mg}, 25 \pm 6 \mathrm{mg}$ and $26 \pm 5 \mathrm{mg}$ in group 2 . While the mean (SD) differences between pre and post of participants' HDL was $7 \pm 0.78 \mathrm{mg}$ in group 1 compared to $4 \pm 0.45 \mathrm{mg}$ in group $2(\mathrm{p}<0.05)$.

Table 1. the levels of TC, TG, LDL and HDL pre and post intervention.

\begin{tabular}{|c|c|c|c|c|c|c|c|c|c|c|c|c|}
\hline \multirow[b]{2}{*}{ Parameters } & \multicolumn{4}{|c|}{ Group $1(n=30)$} & \multicolumn{4}{|c|}{ Group 2(n = 30) } & \multicolumn{4}{|c|}{ Group $3(n=20)$} \\
\hline & Pre & $\mathrm{SD}$ & Post & $\mathrm{SD}$ & Pre & SD & Post & $\mathrm{SD}$ & Pre & SD & Post & SD \\
\hline $\mathrm{TC}(\mathrm{mg} / \mathrm{dl})$ & 262 & 26 & $196^{*}$ & 22 & 255 & 19 & $215^{*}$ & 15 & 286 & 33 & 285 & 32 \\
\hline TG(mg/dl) & 254 & 14 & $200^{*}$ & 12 & 270 & 33 & $240^{*}$ & 10 & 260 & 20 & 262 & 21 \\
\hline $\mathrm{LDL}(\mathrm{mg} / \mathrm{dl})$ & 246 & 11 & $188^{*}$ & 15 & 259 & 13 & $219^{*}$ & 8 & 255 & 23 & 257 & 24 \\
\hline HDL(mg/dl) & 27 & 0.75 & $36^{*}$ & 1.1 & 30 & 1.2 & $35^{*}$ & 1.7 & 29 & 14 & 28 & 1.1 \\
\hline
\end{tabular}

Data are expressed as mean \pm SD

*The mean difference is significant at the 0.05 level compared to pre intervention.

In conclusion, consuming NS seeds and powder can both improve the lipid profile in adults but NS seeds appear to have a stronger effect than NS powder. Therefore, NS is a potential protective natural agent against cardiovascular complications and could be incorporated into a range of foods eaten regularly in Saudi Arabia and in other countries.

1. Nelson R (2013) Prim Care. 40(1): 195-211.

2. Al-Naggar R and Osman N (2017) Scopmed. 7(4): 213-219.

3. Kaatabi H, Bamosa A, Lebda F. (2012) J Family Community Med. 19(3): 155-161. 